\title{
ALUMBRAR EL PRESENTE: ENSEÑAR TENIENDO EN CUENTA A LA MADRE
}

Ma Milagros Montoya Ramos

Fundación Entredos

\begin{abstract}
RESUMEN: La nueva civilización, nacida de la revolución femenina del siglo $X X$, ha traído al mundo grandes ganancias: el final del patriarcado, el orden simbólico de la madre, la diferencia sexual, la autoridad femenina, la política de las mujeres... Y ha dejado al descubierto algunas contradicciones, que vivimos en la enseñanza académica sin que nos atrevamos a abrir el conflicto como son: enseñar y educar sin tener en cuenta que el conocimiento, como la vida, es sexuado; seguir repitiendo unos conocimientos masculinos con pretensiones de ser universales; enseñar con métodos heredados de una escuela jerárquica cuyo centro es el objeto del conocimiento en vez de la relación educativa; no tener en cuenta el origen femenino de la educación porque todas y todos hemos aprendió la lengua materna. Es urgente que la enseñanza de la Historia no se vertebre en las guerras para dar paso a una historia de los sentimientos, las relaciones, los recuerdos, lo que ha pasado y nos pasa a la gente.
\end{abstract}

Palabras clave: Autoridad femenina, diferencia sexual, escuchar y confiar, decir la verdad, María Zambrano, María-Milagros Rivera Garretas.

\section{GIVE BIRTH THE PRESENT: TEACH KEEPING THE MOTHER IN MIND}

ABSTRACT: The new civilization, born of the feminist revolution of the twentieth century has brought large gains to the world: the end of patriarchy, the symbolic order of the mother, the sexual difference, female authority, the politics of women... and has left discovered some inconsistencies, we live in formal education but we dare to open the conflict such as: teaching and education regardless of that knowledge, like life, is sexed, keep repeating about male knowledge with pretensions to be universal; teach methods inherited from a hierarchical school whose center is the object of knowledge rather than the 
educational relationship, not taking into account the female origin of education for all and we've all learned the language. It is urgent that the teaching of history is structured not in wars to give way to a history of feelings, relationships, memories, what has happened and it happens to people.

Keywords: Feminine authority, sexual difference, listen and trust, tell the truth, María Zambrano, María-Milagros Rivera Garretas.

La noticia que, el 26 de diciembre del año 2004, Ilenó todos los informativos fue el terremoto del Océano Índico, con epicentro en la costa oeste de Indonesia y Sumatra, que ocasionó una serie de tsunamis devastadores a lo largo de las islas que bordean las costas de este océano, desde el extremo oriente hasta el continente africano.

Entre las desoladoras noticias ${ }^{1}$ que se sucedieron durante aquellos días, me sorprendió una historia protagonizada por una niña inglesa de 9 años, Tilly Smith, de vacaciones en la isla de Phuket, quien salvó la vida de las y los turistas que se encontraban en aquella playa, una de las pocas en las que no hubo víctimas. Ella vio cómo el mar se retiraba repentinamente y gritó: “¡Viene una ola gigante!". La gente lo oyó y le hizo caso, corrieron hacia el interior de la isla y se salvaron.

¿Por qué ha venido a mi mente de nuevo este hecho, después de siete años, en el momento en que, acogiendo la petición de $M^{a}$ José Clavo Sebastián, intento escribir algo con sentido sobre la educación y la enseñanza hoy? Este relato, que me sorprendió al leerlo ya entonces, me ha acompañado a lo largo de estos años, porque me parecía inaudito que una niña de tan corta edad hubiera salvado a toda la gente que estaba en la playa, aplicando un conocimiento tan alejado de su realidad a un suceso nunca visto. ¿No es sorprendente que una niña de 9 años haya sabido aplicar un saber tan abstracto a una realidad tan poco habitual? Y ¿no es todavía más sorprendente que los mayores, hombres y mujeres, la obedecieran al oír su llamada?

Pensé entonces que ella habría tenido la suerte de encontrarse con una maestra o maestro capaz de enseñar para crecer y para seguir aprendiendo a lo largo de la vida, en vez de limitarse a transmitir conocimientos para copiar, repetir, aprobar el examen y promocionar al curso siguiente. Ahora me pregunto qué pasaría si esta niña fuera una alumna de nuestros centros de enseñanza,

1. Escribí este texto pocos días antes del 11 de marzo de 2011, el día en que sucedió el maremoto y tsunami de Japón, considerado el cuarto terremoto más potente del mundo de los medidos hasta ahora. Todavía se desconocen las consecuencias y el alcance de este terremoto. Hay extensas zonas devastadas o desaparecidas y algunas centrales nucleares han quedado afectadas. He tenido dudas sobre la oportunidad de iniciar mi escrito con esta historia. Pensé borrarlo. Luego caí en la cuenta de que esta evocación es también un acto de amor a las gentes de Japón y un reconocimiento a la educación recibida en las escuelas de ese país. Una educación que ahora se hace visible en una gran solidaridad y una manera serena de acoger el sufrimiento, no con resignación, sino con un paciente compartir lo que tiene cada cual. 
¿habría sabido aplicar lo que estudió sobre los terremotos y los tsunamis con la misma seguridad y precisión que lo hizo Tilly? Probablemente sí, porque quizá también ha tenido, y sigue teniendo, la suerte de estar en el aula con una maestra que no la ha amenazado con las notas, ni con las amonestaciones ni la ha hecho repetir ni copiar, sino que ha dejado que aprenda con balbuceos primero, y con entusiasmo después; dándole tiempo para que interprete el significado de las palabras y, con amor y confianza, pregunte y se pregunte y se equivoque y siga preguntándose hasta que ese saber, válido para su vida, se haya encarnado en ella. María-Milagros Rivera Garretas, una de mis maestras indispensables, ha escrito:

Hay en el mundo un ser maestra que es distinto del ser maestro. Es el de las educadoras que no están en la escuela ni dan clase con la intención de corregir, para mejorarla, la obra de la madre de cada alumna o alumno que tengan a su cargo. Son maestras que están ahí inventando, curso tras curso, maneras de continuar la obra materna, la obra de esa madre concreta que nos inculcó, con un tacto infinito, la competencia del saber estar aquí en el mundo ${ }^{2}$.

Para reflexionar como responsables de la educación y la enseñanza, tan importante es cuestionar nuestra práctica docente como lo es analizar nuestra relación con la realidad que cambia a la luz del porqué se salvó toda la gente que estaba en esa playa. El periodista que escribió el artículo decía que nadie sabe por qué los turistas hicieron caso a la llamada de la pequeña Tilly. Algo debió de resonar en el corazón de cada cual para que al escuchar su grito de alarma, obedecieran reconociendo autoridad a una niña, probablemente desconocida para la mayoría. Este reconocimiento de autoridad fue lo que les salvó ${ }^{3}$ Al unir los dos hechos de esta historia -que Tilly expresara sin titubeos un conocimiento válido para la vida, y que sus acompañantes la escucharan reconociendo su autoridad, autoridad femenina- comprendí que esta alegoría vino a mi encuentro para darme y darnos luz y alumbrar lo que está pasando en la educación y en la enseñanza en esta segunda década del siglo XXI.

\section{Dejarse dar junto al dar activo ${ }^{4}$}

¿Qué está pasando en mi aula, qué me está pasando a mí, qué sentimientos me invaden al abandonar el centro educativo cada día, qué piensan de verdad

2. María-Milagros Rivera Garretas, "Maestras de la aurora del pensamiento", en AA. VV., Treinta retratos de maestras. De la segunda república hasta nuestros días. Madrid, Cuadernos de Pedagogía / CissPraxis, 2005, p. 205.

3. El País el 9 de enero de 2005.

4. María-Milagros Rivera Garretas, Mujeres en relación. Feminismo 1970-2000. Barcelona, Icaria, 2001, p. 17. 
mis compañeras y compañeros, para qué sirven los libros de texto que pasean cada mañana, pacientemente todas y todos los alumnos, por qué repetimos año tras año las mismas cosas y con el mismo método, por qué no me atrevo a "perder el tiempo" escuchándoles a ellas y ellos, por qué me parece una banalidad comunicar las buenas noticias de mis clases...?

Nunca encontramos la ocasión propicia para reconocer o compartir la verdad de lo que sucede día a día en el aula. Las conversaciones entre las y los profesores son casi siempre un lamento, una queja y parece que nos avergüenza compartir una alegría. Nos hemos convertido en oyentes pasivos/as que nos lamentamos, sin advertir que el lamento o la queja refuerza, multiplicándolo, aquello de lo que nos quejamos. La filósofa Chiara Zamboni, en un libro editado este año, cuyo título es "BUENAS NOTICIAS de la ESCUELA", escribe un capítulo que titula "Decir la necesidad", del que yo he recogido estas palabras:

Quien se lamenta demuestra haber perdido un vínculo vital con la cultura y se desliza inadvertidamente hacia los márgenes. Termina por hacer de la cultura un oropel decorativo, un monumento estetizante, algo que parece ser una satisfacción privada, de la que conversar durante la cena. [...]

Decir la necesidad es exactamente estar en el corazón de las cosas tal y como son, aceptar la dependencia que tenemos todos nosotros de la realidad y, además, al hacer esto, entender su sentido. Solamente de esta manera se vuelve a hacer cultura de forma viva. ${ }^{5}$

Para llegar a comprender lo que pasa en este presente se requiere, ante todo, una dosis de humildad que nos obligue a bajar de la tarima que llevamos dentro y sentarnos, sin prisas, a ras de suelo para mirar la realidad del aula con los ojos y la mirada de nuestras alumnas y alumnos. Y después, en vez de mirar para otro lado, hacer una sincera contratación personal entre mí y mí y con el mundo, porque, como dice la filósofa Hannah Arendt:

La educación es el punto en el que decidimos si amamos al mundo lo bastante como para asumir una responsabilidad por él y así salvarlo de la ruina que, de no ser por la renovación, de no ser por la llegada de los nuevos y los jóvenes, sería inevitable. ${ }^{6}$

Educar y enseñar no es lo mismo, pero yo expreso estas dos prácticas siempre unidas, como las dos caras de un misma moneda, porque, si enseño teniendo en cuenta a la madre, educar y enseñar van siempre unidas. Mientras aprendíamos a hablar íbamos aprendiendo también a relacionarnos, a convivir

5. Chiara Zamboni, "Decir la necesidad", en Antonieta Lelario, Vita Cosentino, Guido Armellini (ed.), Buenas noticias de la escuela, trad. Gemma del Olmo Campillo. Madrid, Sabina Editorial, 2011, p. 193.

6. Op. cit., p. 208. 
y a estar en el mundo sin violencia. "Nuestras madres nos han educado para que demos besos al adversario. Apenas empezaba una pelea, inmediatamente intervenían las madres a separarnos y decían: "besito, besito". Lo Ilaman "mamismo", y es también una forma de civilización". Estas palabras de la filósofa Luisa Muraro pertenecen a un artículo que escribió en la Universidad de Verona, en 1999, en plena guerra de los Balcanes, a petición de su alumnado, con el fin de reflexionar en presencia sobre lo que estaba pasando. Y termina diciendo: "Yo os aconsejo escuchar vuestros sentimientos de cuerpos vivos, deseosos, dependientes, y razonar en consecuencia"7.

Hannah Arendt afirma que no se puede educar sin enseñar al mismo tiempo, y considera que es muy fácil enseñar sin educar, porque "cualquiera puede aprender cosas hasta el fin de sus días sin que por eso se convierta en una persona educada" ${ }^{\prime}$. Educar (del latín educare) significa cuidar, alimentar, hacer crecer, sacar lo que cada alumna o alumno lleva dentro agazapado que, si encuentra un maestro que le dé tiempo y luz -los elementos de toda mediación docente- llegará a ser él o ella misma, a encontrarse y seguir creciendo sin perder el gusto por el saber. María Zambrano escribió desde el exilio (entonces en la ciudad de Roma), durante los años 1964 y 1965, más de cien artículos para ser publicados por el Departamento de Instrucción Pública de Puerto Rico en las revistas Semana, Escuela o Educación. Son textos imprescindibles para quienes somos docentes y queremos enseñar y educar teniendo en cuenta a la madre, es decir, reconociendo la autoridad de mi madre, la de cada cual que es madre de la experiencia y madre de la ciencia ${ }^{9}$. María Zambrano desvela la importancia de la relación educativa que se logra dando tiempo para que surja el diálogo donde se dará el intercambio creador en cada cual:

...Ese tiempo que se abre como desde un centro común, como el que se derrama por el aula envolviendo a maestro y discípulos, un tiempo naciente, que surge allí mismo, como un día que nace. Un tiempo vibrante y calmo; un despertar sin sobresaltos. Y es el maestro, sin duda, el que lo hace surgir, haciendo sentir al alumno que tiene todo el tiempo para descubrir y para ir descubriendo [...]. Ignorancia y saber circulan y se despiertan igualmente por parte del maestro y del alumno, que sólo entonces empieza a ser discípulo. Nace el diálogo. ${ }^{10}$

7. Luisa Muraro, "De qué lágrimas Iloradas y de qué sangre y de qué esperma", en Guerras que yo he visto. Saberes de mujeres en la guerra, trad. María Echaniz. Madrid, Horas y horas, 2001, pp. 7-14.

8. Hannah Arendt, Entre el presente y el futuro. Ocho ejercicios sobre la reflexión política, Barcelona, Península, 1996, p. 208.

9. Ana Mañeru Méndez, "La diferencia sexual en la educación", en Nieves Blanco (coord.), Educar en femenino y en masculino. Madrid, Universidad Internacional de Andalucía; Akal, 2001, p. 131.

10. María Zambrano, Filosofía y educación. Manuscritos, ed. Ángel Casado y Juana Sánchez-Gey. Málaga, Ediciones Agora, 2007, p. 118. 


\section{¿Abandono escolar o abandono docente?}

Quienes hemos estado o estáis día a día en el aula ya no podemos quejarnos de lo poco que saben las chicas y los chicos que han permanecido en nuestras aulas ocho horas diarias durante nueve meses a lo largo de 10 años; no podemos hacerlo sin reconocer antes nuestro propio fracaso y sin tomar cartas en el asunto. Lo que está pasando no es ajeno a quienes somos responsables de esos resultados. Después de leer, año tras año, durante más de una década, lo que dicen las estadísticas -nada nuevo que no supiéramos ya antes de ser publicadas- sobre el mal Ilamado abandono escolar, resulta incomprensible que no hayamos escuchado esa llamada de alarma ante nuestro abandono docente. Parece mentira pero es una verdad evidente: no hemos sido capaces de reconocer nuestra responsabilidad en este abandono de las aulas. Un abandono mayoritariamente de alumnos más que de alumnas. Ni siquiera nos hemos atrevido a analizar qué hemos hecho o estamos haciendo mal para conseguir estos resultados en la enseñanza obligatoria. En vez de hablar de abandono escolar tendríamos que precisar más y denominarlo abandono docente y abandono masculino de la escuela masculina. Hemos llegado al punto en que es preciso pensar, decir y hacer algo para no pasar a la historia como la generación docente aquejada de indolencia. Una indolencia que nos empuja a llenar el vacío -ese vacío necesario para la escucha- con más contenidos, más tareas, más libros y más exámenes, en vez de sostenerlo y soportarlo para acoger lo nuevo que ellas y ellos traen al mundo para renovarlo. María Zambrano describe en La tumba de Antígona qué significa ser exiliada y cómo se comporta la gente con quienes llegan:

Hubo gentes que nos abrieron su puerta y nos sentaron a su mesa, y nos ofrecieron agasajo, y aún más. Éramos huéspedes, invitados. $\mathrm{Ni}$ siquiera fuimos acogidos en ninguna de ellas como lo que éramos, mendigos, náufragos que la tempestad arroja a una playa como un desecho que es a la vez un tesoro (la cursiva es mía). Nadie quiso saber qué íbamos pidiendo. Creían que íbamos pidiendo porque nos daban muchas cosas, nos colmaban de dones, nos cubrían, como para no vernos, con su generosidad. Pero nosotros no pedíamos eso, pedíamos que nos dejaran dar. Porque llevábamos algo que allí, allá, donde fuera, no tenían ${ }^{11}$.

He destacado la frase "un desecho que es a la vez un tesoro" porque a mí me ayudó a cambiar la mirada y descubrir la riqueza de muchos de mis alumnos en quienes yo solo veía lo negativo (no sabe, no quiere, me reta, interrumpe...). Y gracias a estas nueve palabras Ilegué a descubrir el tesoro que cada

11. María Zambrano. Premio "Miguel de Cervantes" 1988, Senderos. Los intelectuales en el drama de España. La tumba de Antígona, Barcelona, Anthropos, 1986, p. 259. 
cual Ileva dentro. Cambié mi relación con la realidad y la realidad de alumno despreocupado o retador se transformó en alumno participativo, colaborador e interesado por el saber.

Conviene, sin embargo, no generalizar, ni hacer tabla rasa como si todas y todos fuéramos iguales. Hay infinitas maneras de ser alumnas y alumnos. También hay muchas maestras y algunos maestros que no han abandonado su vocación y reconocen que han elegido la parte más delicada de la obra de la civilización; por ello agradecen que cada día las y los alumnos Ileguen contentos y puntuales a sus clases para aprender y enseñar algo nuevo y original (enraizado en el origen). Han experimentado que aprender y enseñar se hace siempre en relación, al menos entre dos. Porque no enseña el departamento ni el claustro de profesores (donde también hay profesoras) ni la administración ni el mal Ilamado cuerpo docente. Enseño y aprendo yo y tú y tú: siempre cuerpos de mujeres o de hombres con la riqueza significativa (significar quiere decir dejar señal) de su diferencia sexual. El cambio se hace siempre en primera persona, desde mi ser mujer y desde tu ser hombre, y en relación de confianza con otra u otro, cuando he descubierto la necesidad y me atrevo a poner en práctica lo que nace de mi libertad y de mi deseo. Cada cual puede decir yo soy escuela, yo soy educación, y lo que yo hago o digo nadie puede hacerlo por mí. "Si algo echas en falta, ponte en marcha" es la consigna que hemos acuñado las mujeres de la Fundación Entredós ${ }^{12}$ para no lamentarnos con aquello de "se podría" hacer más o para no caer en un deseo desmedido que no está al alcance de mis posibilidades y puede quedarse en una ensoñación.

Nuestro compromiso como responsables de la enseñanza y de la educación ya no es lograr la igualdad de oportunidades en el acceso al conocimiento ni reclamar la igualdad de derechos ante la ley, que hoy son una realidad, está en reconocer y acoger lo heredado y hacerlo nuevo, presente aquí y ahora, convirtiéndolo en práctica viva para llevar a buen término ese cambio todavía pendiente en la enseñanza reglada. Con un conocimiento tan vivo como el saber de Tilly Smith y un compromiso tan fuerte como el de Rachel Corrie, una periodista norteamericana que fue asesinada deliberadamente en Palestina el 16 de marzo de 2003 por una excavadora conducida por un soldado israelí cuando intentaba evitar el derribo de otra casa ${ }^{13}$.

Desde hace tiempo, quizá demasiado, seguimos enseñando y repitiendo el pensamiento heredado del racionalismo de los siglos XVIII y XIX, que nos impide hacer un vacío para acoger lo nuevo que traen las alumnas y los alumnos a comienzo del curso escolar, hacer significativa la diferencia sexual en la educación y en la historia, y reconocer la autoridad femenina, que no es otra cosa que reconocer a nuestra madre, la de cada cual, como la primera maestra magistral.

12. Ver www.unapalabraotra.org/entredos/

13. Rachel Corrie, Carta a su madre en Duoda, Revista de Estudios Feministas, n 26, 2004, p. 23. 
Esos conocimientos abstractos y pretendidamente neutros y universales "no hay quien los entienda, ni sirven para nada", me decían mis alumnos de Diversificación, refiriéndose a la historia; y lo peor es que matan el deseo de aprender y provocan un aburrimiento tal que terminan abandonando el centro escolar ${ }^{14}$. Más que un saber nacido de la experiencia enseñamos un conocimiento académico, selectivamente masculino, que tiene su origen en la creación de las universidades -donde las mujeres no tenían lugar- y que hemos heredado del racionalismo, donde las mujeres seguimos estando ausentes aunque seamos mayoría en las aulas, los pasillos y los claustros de los centros educativos desde la educación infantil hasta la enseñanza universitaria. En nuestros centros educativos la madre no tiene cabida porque no reconocemos la autoridad de la lengua materna, y al enseñar no tenemos presente cómo aprendimos a hablar, en esa relación amorosa y de confianza en la madre o en quien nos haya amado en su ausencia.

\section{Reconocer autoridad femenina}

"Al principio de la autoridad está, efectivamente la madre, para mujeres y para hombres", afirma Luisa Muraro, quien sostiene que el principio materno es, en rigor, pre-histórico y por eso la autoridad es sucedánea de la potencia materna. "El principio materno, por su posición pre-histórica, es un medidor sin medida".

Estamos en una nueva civilización, la del orden simbólico de la madre, que se ha hecho visible en el último tercio del siglo XX con la única revolución que ha triunfado en el siglo pasado: la revolución de las mujeres. Una revolución que ha hecho significativa la diferencia de ser hombre y de ser mujer y el reconocimiento de la madre, como nuestra primera maestra magistral. Es una revolución simbólica, hecha con palabras verdaderas y que no necesita cubrir etapas ni preparar estrategias, sino que se abre sin violencia en cada cual. Luisa Muraro lo explica de esta manera;

Pienso que estamos de acuerdo al decir, y esto es ya un lugar común, que las mujeres han hecho la revolución del siglo, la única que ha llegado felizmente a puerto en el siglo XX. Se trata de una revolución femenina, como ha dicho el sociólogo inglés Anthony Giddens [...]. Pensad en un tejido de lana que, al soltarse un punto, se va deshaciendo por completo. Pensad en una frase que, cambiando un signo, cambia totalmente su significado. En el orden simbólico, esto quiero decir, no valen las cantidades y las estadísticas, sino la intensidad, es decir, el sentido que toman o pierden las cosas junto a las corrientes que se mueven con los pasos de un sentido al otro.

14. Ver Cuadernos de Pedagogía, n 410, Marzo 2011, p. 10. 
Hoy existe una lengua de las mujeres, esto es, un juego abierto sobre el sentido de la diferencia sexual, que se presta a liberar no sólo el significado de las palabras de los prejuicios del patriarcado, comenzando por la palabra "mujer", sino también el significado del artículo determinado femenino plural: "las" mujeres. ${ }^{15}$

Entendemos como un cambio de civilización lo que se ha producido en el mundo en los distintos ámbitos de la vida -cultural, económico, político, social, laboral, de relaciones entre los sexos y de los sexos y también educativo- donde estamos las mujeres, que hoy estamos en todas partes. Ha sido «una revolución inesperada» que ha desbordado los paradigmas existentes con sus códigos, su jerarquía, sus lenguajes y su organización. Aunque los datos estadísticos indican un mayor número de mujeres en el acceso al mercado del trabajo y en la universidad, institucionalmente no han sabido interpretar este cambio. Lia Cigarini cuenta que los sindicatos no habían registrado este dato o pensaban que no era significativo, porque según su organización «las mujeres se convertían en "trabajadores" a todos los efectos. Así, no había necesidad de modificar el modo de pensar sobre el trabajo ${ }^{16}$.

Dentro de la escuela, sucede algo parecido, pues aunque los datos constatan la superioridad de las mujeres en los estudios medios y superiores -excepto en algunas especialidades de formación profesional- el mal Ilamado cuerpo directivo y cuerpo docente no lo ha tomado en consideración o no lo encuentra significativo. La escuela, desde la etapa infantil hasta la universidad, por ahora, sigue siendo una institución masculina que se niega a reconocer la autoridad de la madre como la primera maestra, y por eso se sigue hablando en neutro, que no existe, o en genérico masculino universal -en el que las mujeres pasamos a ser alumnos o profesores- y así no se significa la diferencia sexual. El espacio escolar, a pesar de la mayoritaria presencia femenina, no se ha dejado transformar por el más relacional de las mujeres.

¿Qué significa poner en juego el orden simbólico de la madre en la educación? Significa reconocer en el aula a la madre real y concreta como la primera maestra, cuidando que el pensamiento y la palabra no se separen del cuerpo y de la vida e inventando maneras de enseñar para continuar la obra materna. Poner en juego el orden simbólico de la madre significa también cuidar la relación educativa y reconocer el sentido libre de la diferencia sexual para enseñar a las niñas no a ser iguales a los niños, sino a aprender y crear desde su diferencia femenina; y enseñar a los niños a distinguir y acoger lo que sigue siendo valioso desde la diferencia libre de ser hombre y a transformar lo que no lo es para hacer que la convivencia entre los sexos sea política, o sea, no violenta.

15. Luisa Muraro, La verdad de las mujeres, trad. María-Milagros Rivera Garretas, en "Duoda, Estudios de la diferencia sexual", no 38, 2010, pp. 69-124.

16. Lia Cigarini, «Introducción» en AA.VV., Una revolución inesperada. Simbolismo y sentido del trabajo de las mujeres, trad. de Carolina Ballester Meseguer. Madrid, Narcea, 2001, p. 18. 
Esta revolución femenina ha dejado al descubierto algunas contradicciones que cada día van quedando más alejadas de lo que hoy buscan las chicas y los chicos. Contradicciones que vivimos dentro de la enseñanza reglada sin que nos atrevamos a abrir el conflicto. Una grave contradicción es enseñar y educar sin tener en cuenta lo que somos, cuerpos de mujer y cuerpos de hombre, y sin hacer significativa esa diferencia, porque el conocimiento es sexuado. También es un contradicción seguir repitiendo unos conocimientos masculinos con pretensiones de ser universales y enseñar repitiendo los mismos métodos con los que aprendimos, propios de una escuela jerárquica donde la relación educativa no se tiene en cuenta; solo se atiende al objeto del conocimiento no al sujeto, las y los alumnos, que son el centro de la autoridad docente. Autoridad, como dice Hannah Arendt, es una palabra que deriva del latín augere que significa "aumentar", "hacer crecer". La educación, en su origen, es femenina, sea ejercida por profesores o profesoras, porque ambos hemos aprendido a hablar en relación de confianza con la madre. Reconocer la autoridad femenina es reconocer el sentido original de la educación. Al acudir a esa experiencia primera que, aunque no la recordemos, ha quedado impresa en nuestras entrañas es garantía de éxito educativo, que es diferente de exigir resultados inmediatos. Educar es hacer crecer, y el crecimiento personal Ilega a su tiempo, que no suele coincidir con el nuestro. Pero llega siempre y gracias a la relación y la palabra de quien ha confiado en las capacidades de aquel alumno o alumna.

\section{¿Cómo enseñamos y aprendemos?}

La mediación de las y los docentes, según María Zambrano, es la mediación más cercana a la de la madre, que nos da a luz después de haber hecho disponible su cuerpo durante nueve meses (un curso escolar) y nos enseña a hablar, en una relación de amor y confianza en su criatura, para hacernos viables en el mundo. Es la más cercana a la madre porque el o la maestra media con el ser mismo en tanto crece. "El filósofo, el sabio, el artista, son mediadores de una especie colindante con el maestro porque trasmiten algo, verdad, ciencia, belleza; más no en una forma personal, directa, sino a través de una obra"17.

Ser maestra o maestro es una vocación, no un trabajo como los demás, una vocación que nos hace crecer a quienes la ejercemos y a quienes vienen a clase todos los días. Esto no quiere decir que no tengamos que enseñar, pero no con métodos unidireccionales, con lecciones magistrales, o llenando pizarras, digitales o no, despreciando así la escucha y la relación educativa que es donde se aprende. Algo tengo, tenemos que hacer, porque de seguir así lo que hoy reconocemos como una civilización, buena para las mujeres y también para los hombres, no perdurará mucho tiempo. La historia no es un tiempo de

17. María Zambrano: L'art de les mediacions (Textos pedagògics), ed. Jorge Larrosa i Sebastián Fenoy. Barcelona, Publicacions de la Universitat de Barcelona, 2002, pp. 103-114. 
progreso sucesivo, como nos han enseñado. Hoy sabemos que hubo grandes civilizaciones femeninas en la Europa medieval, con una duración de más de 200 años, como la civilización cátara y la de las trovadoras cuya frontera no era un espacio de confrontación ni de lucha, sino "un espacio desestructurado entre dos civilizaciones que propicia el intercambio entre ambas"18. Esas civilizaciones desaparecieron por la represión conjunta del poder político y el poder del papa. La destrucción de las cátaras, en los manuales de historia se suele Ilamar la Cruzada Albigense.

¿Cómo hicimos el primer aprendizaje: aprender a hablar, a nombrar las cosas? ¿Qué recordamos de lo aprendido en la escuela? ¿Enseñamos historia, gramática, física o el amor que tiene la profesora o el profesor por lo que enseña?

En realidad enseñamos el amor por lo que enseñamos. Es decir, que la experiencia de enseñar y de aprender es una experiencia amorosa. Pero en la enseñanza reglada, más que el amor se hace visible la lógica del poder, de los derechos, de la fuerza de la ley, que es un ámbito distinto y da lugar a realidades diferentes.

El primer aprendizaje, la lengua materna, lo hicimos en esa relación de confianza que se da entre la criatura y su madre ${ }^{19}$; y en todo proceso de aprendizaje existe siempre una confianza, explícita o implícita, entre docente y discente, aunque no se reconozca públicamente. No se reconoce porque en la enseñanza reglada la autoridad de la madre está negada o ausente y el amor y la confianza no encuentran espacio. La autoridad no es de nadie, se reconoce o no. Se crea en relación. Nace del amor a lo otro y a los otros y otras que no soy yo. La autoridad hace crecer a quien la reconoce y a quien acepta ese reconocimiento. El poder se impone con la fuerza de la ley o la violencia de las armas. El poder actúa en representación, marca límites sin tener en cuenta al otro o a la otra y se impone legalmente.

No es la confianza lo que predomina en las relaciones docentes, sino, casi diría, que es la desconfianza. Confiar no parece ser una cualidad muy cotizada para tener éxito social. Sin embargo, si miramos al origen, a la relación materna, descubrimos que la confianza está en "el sustrato mismo de nuestro $\operatorname{ser}^{\prime \prime 20}$ y permanece en nuestro interior como garante de una riqueza inagotable.

Este amor que aprendimos debería ser materia de aprendizaje también en la enseñanza reglada, debería hacerse visible en la política, porque ya hemos

18. María-Milagros Rivera Garretas, La diferencia sexual en la historia. Valencia, Publicacions de la Universitat de València, 2005, p. 162.

19. "El cuerpo humano sufre cuando tiene que estudiar discursos porque se le obliga a aprender en una relación de fuerza. No de amor, como cuando aprendió a hablar. En realidad, la lengua materna no la olvidamos nunca porque es la escuela del primer amor." MaríaMilagros Rivera Garretas, "Maestras de la aurora del pensamiento", epílogo en Treinta retratos de maestras. De la segunda república a nuestros días. Madrid, Cuadernos de Pedagogía / CissPraxis, 2004, p. 206.

20. María Zambrano, Hacia un saber sobre el alma. Madrid, Alianza Editorial, 2000, 106. 
dicho que política es todo lo que la gente hacemos en relación para evitar la violencia ${ }^{21}$. El amor es lo que nos ha dado la vida y lo que nos sostiene también en el mundo. No es el dinero, aunque pueda parecer lo contrario. Buscamos ser felices y aunque a veces nos equivocamos, en el fondo siempre buscamos querer y que nos quieran. Pero el amor se ha quedado reducido, en nuestro presente, a una palabra romántica, carente de sentido político y es necesario hacerla visible también en la educación porque "no es una historia de amor, aunque el amor esté presente en ella. Es decir, está justo fuera esperando el modo de entrar"22.

En definitiva cuanto más se parezca un centro educativo a una casa mejor será la educación porque está más cerca del origen. Por eso la educación infantil es la mejor porque el saber es un placer, se deja que circule la creatividad y las niñas y niños aprenden, y aprenden mucho, entre risas y juegos, en relación con su maestra, que es su autoridad y con las otras niñas y niños, sin competitividad, pero con mucha competencia de saber estar y de querer aprender.

El amor no se puede enseñar con la fuerza de la ley, a golpe de sanciones o expedientes disciplinarios. Así se marcan límites, pero no se enseña a convivir en la disparidad ni a pedir perdón ni a que los chicos respeten a las chicas. El amor se enseña con el amor. Así nos lo enseñó la beguina Hadewijch de Amberes, quien escribió en el siglo XIII en una carta a una amiga unas frases preciosas, que dicen: "Querida mía, todas las cosas hay que buscarlas con lo que ellas mismas son: la fuerza con la fuerza, la astucia con la astucia, la riqueza con la riqueza, el amor con el amor, el todo con el todo y, así, siempre, las semejantes con las semejantes. Esto basta, nada más." ${ }^{23}$

María Zambrano dice que el amor es una creación espiritual como lo es el arte y la ciencia: "La mujer tiene una mayor cercanía con la naturaleza, pero no se queda tampoco en ella, pues de ser así, sería otra especie distinta del hombre; ella también crea, y su primera creación es eso que llamamos amor. El amor es una creación espiritual como el arte, como la ciencia". ${ }^{24}$

El amor es el método. Yo estudié historia porque me entusiasmaba la manera de explicar de mi profesora de bachillerato. Todavía conservo sus apuntes. De las otras asignaturas no recuerdo casi nada, porque recordamos lo que aprendimos con amor. Por eso la lengua materna nunca se olvida, porque es la escuela del primer amor.

21. María-Milagros Rivera Garretas, La diferencia sexual en la historia, Valencia, Publicacions de la Universitat de València, 2005, p. 163.

22. Jeannette Winterson, La niña del faro, Barcelona, Lumen, 2005, p. 121.

23. Hadewijch, Poesie visioni lettere, sel. y trad. de Romana Guarnieri, Génova, Marietti, 2000, p. 113 (Lett. 7).

24. María Zambrano, El pleito feminista: seis cartas al poeta Luis Álvarez-Piñer (19351936), a cargo de Maite Alvr-Piñer Méndez y María-Milagros Rivera Garretas, en "Duoda, Revista de Estudios Feministas nº 23 (2002), pp. 205-218. 


\section{¿Qué enseñamos y para qué?}

No es fácil armonizar un conocimiento tan fragmentado y con tanta especialización. Pero es necesario hacerlo para que "las y los nativos digitales" -así denominan ahora a quienes antes de sentarse en un aula de educación infantil ya traen en su cuerpo muchas horas de interacción y aprendizaje con los videojuegos y otros medios digitales- no dejen las aulas vacías. Las y los profesores y las madres y padres somos "inmigrantes digitales" recién llegados a su mundo. Los juegos interactivos han cambiado la manera de acercarse al saber en los y las nativas digitales. No necesitan ni soportan leer ni escuchar mucho tiempo; en pocos minutos descubren la solución del problema que le plantea su juego electrónico, del que reciben una respuesta-recompensa inmediata. El razonamiento vendrá después. Al cambio epistemológico que ha traído el feminismo, al situar en primer plano al sujeto en vez de al objeto de conocimiento y demostrar que se aprende en relación, se ha unido en esta última década la generalización de la informática donde se aprende interactuando con rapidez y sin miedo alguno, experimentando así el placer de una recompensa inmediata. Después vendrá el razonar, cuestionar, investigar y hacer suyo ese saber.

Muchas profesoras y algunos profesores se están cuestionando lo que enseñan y cómo tendrían que adaptar el método o camino que cada alumna o alumno tiene que recorrer. Lo están haciendo en relación, con docentes de distintos niveles y de materias afines o/y con las y los maestros del mismo curso o nivel educativo, e incluso entre docentes de distintas etapas para seleccionar y consensuar unos conocimientos mínimos y evitar la repetición de los mismos.

En algunas materias, como en la Educación Física, Marisa Gismero ha puesto en cuestión el mismo nombre de la asignatura por la contradicción que conlleva denominar educación física a lo que es una educación de los cuerpos sexuados. Ella propone denominarla Educación Corporal, que es un nombre más significativo y más adecuado a lo que se enseña o debe enseñarse sin cancelar la diferencia de ser mujer y de ser hombre.

En esta disciplina se hace más evidente la necesidad de tener en cuenta los cuerpos, en las demás asignaturas también, pero no se muestra tan obvio, porque nos parece que educamos el espíritu, la mente, la inteligencia, aunque en realidad todo es cuerpo, pues pensamos, amamos, aprendemos, cantamos, etc. siempre con el cuerpo. Los cuerpos son, siempre, cuerpos de mujer o cuerpos de hombre, y si en las clases de educación física se hiciera evidente esta realidad, no seguiríamos impartiendo clases a cuerpos masculinos (incluyendo en ellos el cuerpo de las mujeres) con métodos y contenidos heredados de las escuelas de otros siglos, que, con pequeñas variaciones, se siguen impartiendo en el siglo xxı. Es decir, hoy todavía las escuelas siguen siendo masculinas donde las alumnas son alumnos. Si no fuera un hecho real, podría resultar grotesco decir que los profesores y también las profesoras consideran que las mujeres somos iguales a los hombres. ¿Tan invisibles son las chicas como para 
no verlas? ¿Para no ver que su cuerpo es diferente y necesita una atención y educación corporal -que no física- que tenga en cuenta la diferencia del cuerpo femenino? Si en la clase de educación física no son capaces de apreciar la diferencia sexual ¿qué se puede esperar de otras materias en las que lo importante son los contenidos y las alumnas y alumnos, casi siempre, son la clase o el curso?

En Historia, se sigue enseñando con unos libros de texto elaborados a partir de unos contenidos parciales que ofrecemos como únicos y universales. Y, a pesar de la permanente sensación de fracaso y hastío que produce esta historia y su manera de enseñarla, hay una silenciosa resignación y una renuncia al placer de enseñar y de aprender, esperando que alguien desde fuera nos libere de este letargo. La reacción habitual es la queja continuada que reproduce, multiplicándolo aquello de lo que nos quejamos: es imposible enseñar, no quieren aprender, no les interesa estudiar. Urge un cambio de mirada para saber leer la realidad tal cual es, no como querríamos que fuera. De la política de las mujeres hemos aprendido que lo que podemos hacer para cambiar la realidad es cambiar nuestra relación con ella y de esta manera la realidad se transforma. Así es como hacen las madres, en vez de quejarse de la inteligencia, carácter, altura o aspecto físico de sus criaturas, suelen fijarse en que su hija es única y singular, distinta, y maravillosa y así llega a ser viable en el mundo al que enriquece con su presencia.

Quienes amamos la enseñanza y amamos la historia, desde hace algunos años, estamos pensando, escribiendo, y poniendo en práctica una mediación didáctica para el alumnado de la educación secundaria obligatoria. Varias profesoras y profesores y otras mujeres que educan y enseñan en la vida diaria nos reunimos quincenalmente, en el espacio de pensamiento y práctica educativa que Ilamamos "Una historia verdadera" en reconocimiento a María Zambrano, quien en su obra "La tumba de Antígona" dice que debajo de las cosas que ocurren suceden otras que hacen una historia verdadera. La historia de las Antígonas que soportan la historia, no porque sean dominadas por ella sino porque no están haciéndola, es decir, no es su historia la que aprenderemos en los libros de historia. De este trabajo compartido hay diversas publicaciones ${ }^{25}$.

25. M Milagros Montoya Ramos, Enseñar: una experiencia amorosa. Madrid, Sabina Editorial, 2008; M Milagros Montoya Ramos y Juan Cantonero Falero, En femenino y en masculino: la diferencia sexual en el aula. "Duoda, Estudios de la diferencia sexual", 2005, 29, pp. 109-127; Ma Milagros Montoya Ramos, La historia verdadera, Duoda, Estudios de la diferencia sexual", 2006, 30, pp. 173-177; Cuadernos de Pedagogía nos 293, 299, 306, 333, 335 y 337. 


\section{Una mediación educativa desde el saber de la experiencia. La prehistoria del mundo y mi prehistoria ${ }^{26}$.}

Este curso escolar 2010-2011 nos hemos atrevido a cuestionar lo que hay -lo que se enseña y cómo se enseña la historia en la educación obligatoria- y crear algo nuevo en el acercamiento a la Pre-historia. El deseo y la necesidad nos han empujado a ello. Porque a los alumnos y a las alumnas les resulta chocante empezar a estudiar historia y descubrir que empezamos por lo que no es historia, sino lo que acontece antes de que nazca la historia. Ángeles Querol también hace notar este salto epistemológico:

De las distintas partes en las que, de forma más que arbitraria, dividimos la Historia desde hace siglos, a la primera, a la que hoy denominamos Prehistoria es, además de la más reciente en su incorporación a la lista, la más desconocida. [...] Y curiosamente se trata la parte de la Historia humana que presenta una cronología más larga

Se trata de un tipo de Historia humana muy diferente, epistemológicamente distinta, ya que ni se construye mediante el estudio de los textos escritos - porque no los tienen- ni conserva memoria de los hechos y los personajes heroicos. Lo que conserva -los restos arqueológicos- nos hablan de cómo se alimentaban, del tamaño de los grupos y de sus territorios, de las maneras de construir una choza o una ciudad, de formas de enterrar a la gente, de estilos de tallar piedras, de modelar cuencos o de inventar cestos y vestidos. [...]

Nos habla, en definitiva, de cuestiones que tan solo en las últimas décadas han comenzado a interesar a la ciencia histórica. ${ }^{27}$

En las últimas décadas del siglo XX y en el siglo XXI, gracias a las nuevas técnicas de investigación, la prehistoria se ha convertido no solo en el estudio y evolución de las homínidas y homínidos, sino que se ha diversificado: se conocen las especies vegetales y animales que existieron hace miles de años, se puede saber si las y los neandertales hablaban, tenían tecnología, gestionaban el fuego, etc.

Podríamos decir que la Pre-historia es uno de los conocimientos de más actualidad. El problema lo tenemos en cómo acercamos este saber a nuestro alumnado sin dejarlo en la abstracción y perdido en el tiempo. La necesidad de acercarles a este conocimiento sin que perdieran el interés por lo que sucedió hace tanto tiempo nos Ilevó a buscar un método original: que las alumnas y los alumnos se acerquen a la prehistoria desde su historia personal. No en el

26. Este texto es de autoría compartida: Raquel Martín Sánchez, Juan Cantonero Falero, Patricia T. Cañadas, Marisa Gismero, Josefa Otero, Mon García Quiroga.

27. María Ángeles Querol, De la Prehistoria a la Edad Media, Volumen I, en Historia de las mujeres en España y América Latina. Madrid, Cátedra, 2005, pp. 21-22. 
sentido de hacer un eje cronológico de su tiempo vivido y el tiempo de sus padres y abuelos, sino haciendo una historia de los sentimientos, las relaciones, los recuerdos ${ }^{28}$, como dice María Zambrano.

Si consideramos que la historia comienza con el documento escrito, podremos descubrir que también en nuestras vidas hay una historia y una prehistoria. El tiempo prehistórico personal es aquel tiempo de infancia en el que todavía no sabíamos ni escribir ni interpretar un escrito (leer). Sin embargo, en esa etapa tan fundamental de cada vida humana, sabíamos las cosas más importantes para vivir y convivir, como son: hablar, cuidar y cuidarme, andar, bailar; también los nombres de las cosas, cantar y contar historias, jugar en soledad y con otros y otras, Ilorar y reír, distinguir lo que es peligroso, sentir el miedo; comer, amar, vestirme, lavarme, etc.

Siguiendo este método o camino de búsqueda simbólica en la propia vida y en el tiempo prehistórico de la humanidad se pueden establecer dos aspectos:

a) Indagación en mi propia vida pre-histórica.

b) Relación con la evolución de las y los prehistóricos.

Para hacer el recorrido por la propia infancia necesitamos hacer una investigación, preguntándome y preguntando a quienes estuvieron a mi lado en esos años en los que yo no sabía ni hablar ni leer ni escribir. Preguntas que nunca serán las mismas para cada alumna o alumno. A modo de propuesta sugerimos algunas preguntas que no son cerradas, sino que pueden ampliarse y cambiarse para que tengan sentido para las alumnas y alumnos:

Además de esta introducción didáctica, es importante tener en cuenta la cronología, el tiempo histórico, que también puede relacionarse con el tiempo biográfico personal: porque ambos están vinculados con los útiles, la tecnología y los restos arqueológicos. Advertimos también que casi todas las preguntas hacen referencia a los orígenes, al tiempo más antiguo, que se ha llamado Paleolítico, y es también el tiempo de Lucy, la primera mujer en la historia de la humanidad, y es de origen africano.

28. María Zambrano, Persona y democracia. La historia sacrificial. Barcelona, Anthropos, 1998, p. 130. 


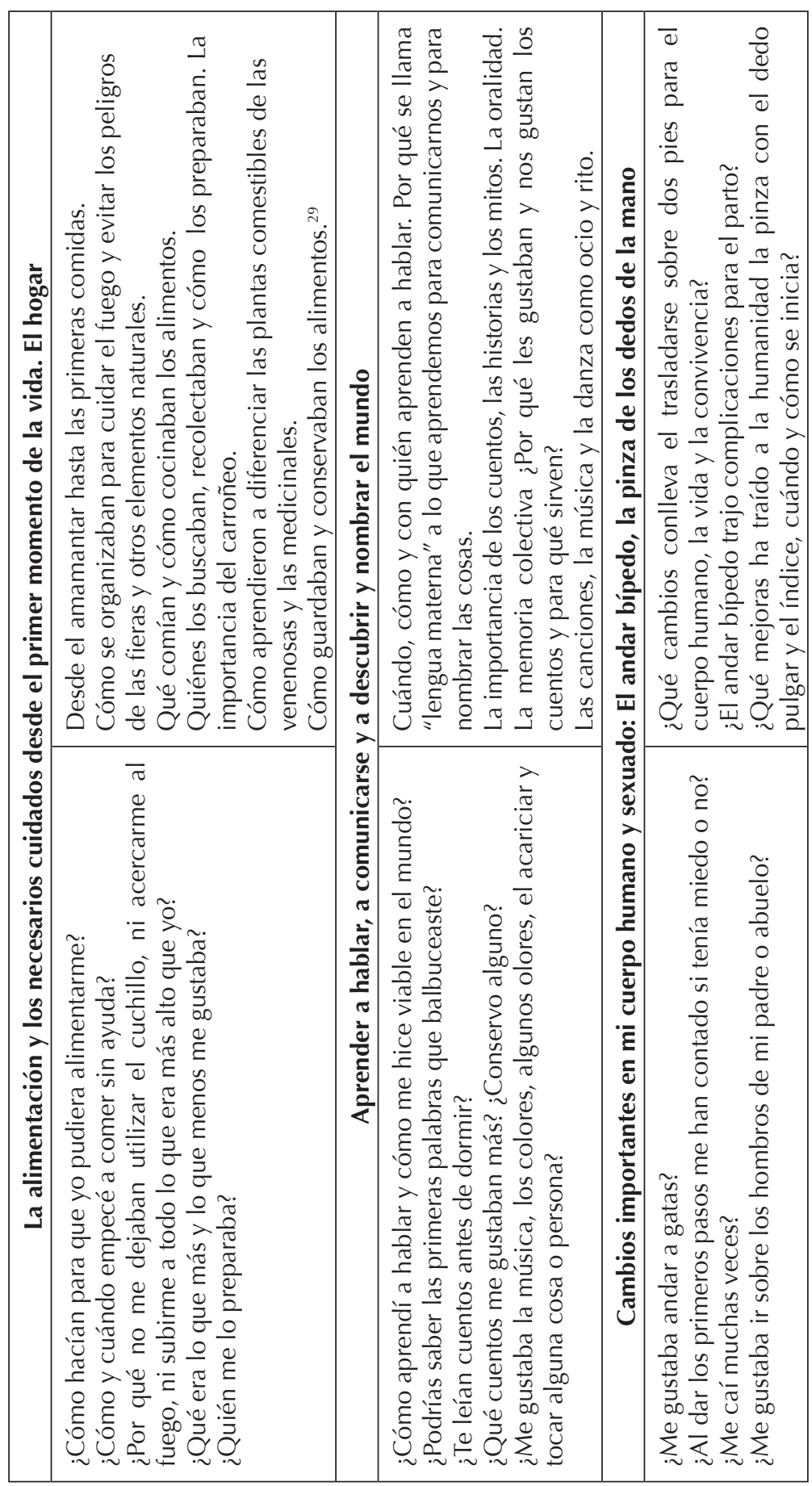

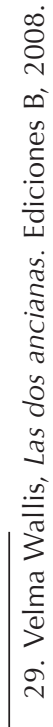


Ma MILAGROS MONTOYA RAMOS

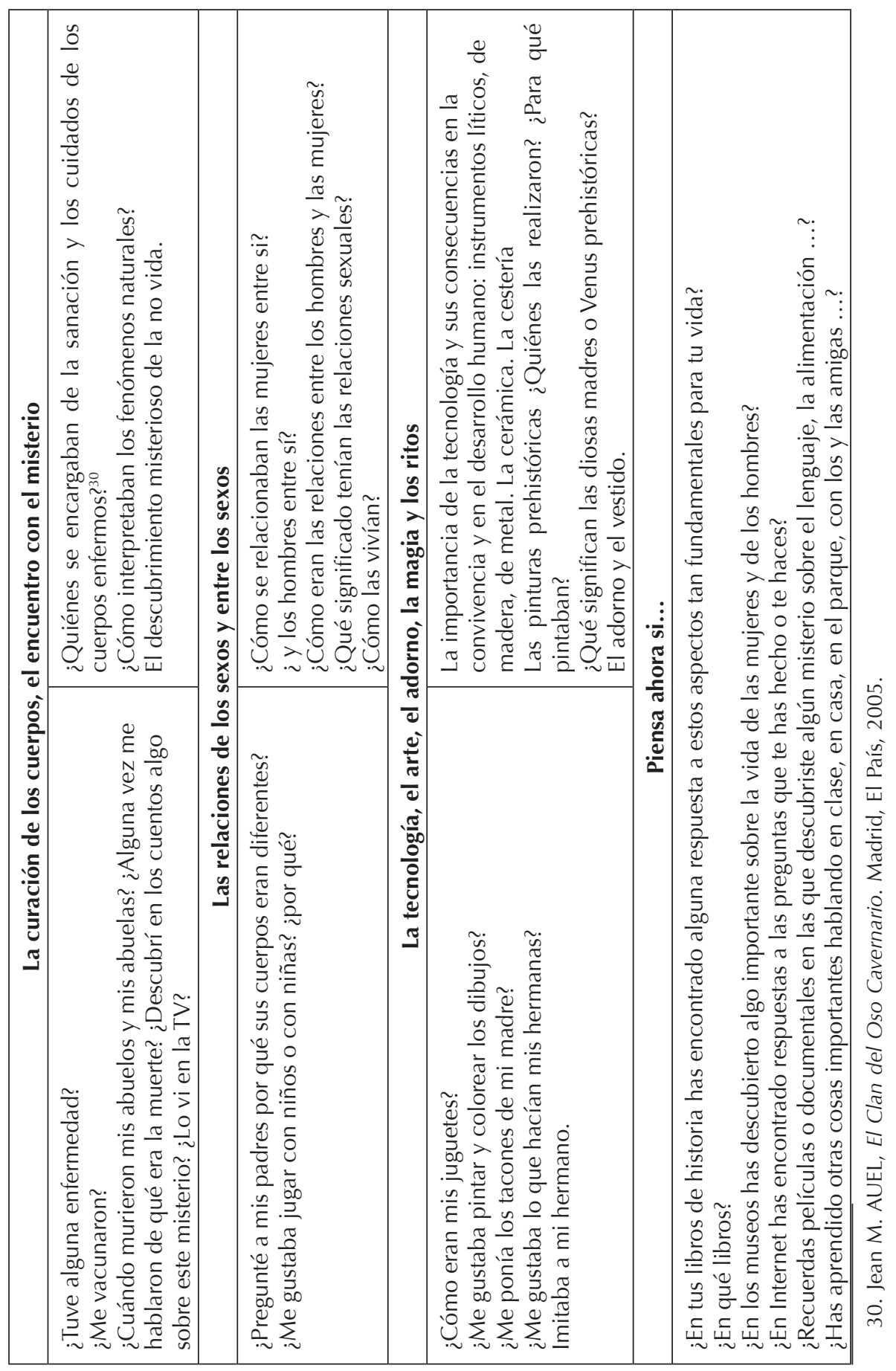


Si te atreves a poner en práctica esta metodología nos gustaría saber cómo ha resultado. Puedes enviarlo a este correo electrónico mmilagros. montoya@gmail.com y escribir un comentario en www.espaciounahistoriaverdadera.blogspot.com

Gracias porque has Ilegado hasta aquí. El texto es de quien lo lee porque al leerlo cobra nueva vida y nace otra realidad que alumbra el presente porque lo ilumina $y$, sobre todo, porque algo nace en ti que te renueva y renueva al mundo. Porque, como ha escrito la poeta Ana Mañeru:

Detrás de una palabra, tan solo de una sola, renace el mundo entero ${ }^{31}$.

\section{Bibliografía}

AA. VV., Treinta retratos de maestras. De la segunda república hasta nuestros días. Madrid, Cuadernos de Pedagogía / CissPraxis, 2005.

AA. VV., La diferencia de ser mujer. Investigación y enseñanza de la historia. Barcelona, Duoda, Centro de Investigación de Mujeres, 2005, en CD-ROM.

AA.VV., Una revolución inesperada. Simbolismos y sentido del trabajo de las mujeres, trad. de Carolina Ballester Meseguer. Madrid, Narcea, 2001.

ARENDT, Hannah, Entre el presente y el futuro. Ocho ejercicios sobre la reflexión política. Barcelona, Península, 1996.

ARNAUS, Remei y PIUSSI, Anna Maria (coords.), La universidad fértil. Mujeres y hombres, una apuesta política. Barcelona, Octaedro, 2010.

CABA, Angels; CASANOVA NADAL, Mercedes y EDO BENAIGUES, María Joseph, El siglo XX en primera persona. Barcelona, Octaedro, 2001.

CIGARINI, Lia, "Introducción", en AA.VV. Una revolución inesperada. Simbolismo y sentido del trabajo de las mujeres, trad. de Carolina Ballester Meseguer. Madrid, Narcea, 2001.

HADEWIJCH, Poesie visioni lettere, sel. y trad. de Romana Guarnieri. Génova, Marietti, 2000, 113 (Lett. 7).

MAÑERU MÉNDEZ, Ana, "La diferencia sexual en la educación", en Nieves Blanco (coord.), Educar en femenino y en masculino. Madrid, Universidad Internacional de Andalucía - Akal, 2001.

— "Recetas que no fórmulas", en SOFÍAS, Escuela y educación ¿hacia dónde va la libertad. Madrid, Horas y horas, 2002.

31. Ana Mañeru Méndez y J. M. Báez Arrufaf, De vuelta a mí. Madrid, A. Mañeru 2000, p. 89. 
PIUSSI, Anna Maria y MAÑERU MÉNDEZ, Ana (coords.), Educación, nombre común femenino. Barcelona, Octaedro, 2006.

MURARO, Luisa, "De qué lágrimas lloradas y de qué sangre" y de qué esperma, en Guerras que yo he visto. Saberes de mujeres en la guerra, trad. María Echaniz. Madrid, Horas y horas, 2001.

- La verdad de las mujeres, trad. María-Milagros Rivera Garretas, en "Duoda, Estudios de la diferencia sexual", n 38, 2010.

- Enseñar la libertad, en "Duoda, Revista de Estudios Feministas", trad. de María-Milagros Rivera Garretas, nº 67, 2004.

- Hacer política, escribir historia. (Notas de trabajo), trad. de María-Milagros Rivera Garretas, en "Duoda, Papers de treball", n 2, 1991.

QUEROL, María Ángeles, De la Prehistoria a la Edad Media, Volumen I, en Historia de las mujeres en España y América Latina, Madrid, Cátedra, 2005.

RIVERA GARRETAS, María-Milagros, La diferencia sexual en la historia, Valencia, Publicacions de la Universitat de València, 2005.

- Mujeres en relación. Feminismo 1970-2000. Barcelona, Icaria, 2001.

- (coord.), Las relaciones en la Europa medieval. Valencia, Tirant lo Blanc, 2006.

ZAMBRANO, María, Filosofía y educación. Manuscritos, ed. Ángel Casado y Juana Sánchez-Gey. Málaga, Agora, 2007.

- L'art de les mediacions (Textos pedagògics), ed. Jorge Larrosa i Sebastián Fenoy. Barcelona, Publicacions de la Universitat de Barcelona, 2002.

- Hacia un saber sobre el alma. Madrid, Alianza Editorial, 2000.

_ "El pleito feminista: seis cartas al poeta Luis Álvarez-Piñer (1935-1936)", a cargo de Maite Alvz-Piñer Méndez y María-Milagros Rivera Garretas, en Duoda, Revista de Estudios Feministas, no 23, 2002.

- Persona y democracia. La historia sacrificial. Barcelona, Anthropos, 1998. 